\title{
Research on the Social Responsibility of Tourism Enterprises from the Perspective of the Stability of Sichuan-Tibetan Region
}

\author{
Deng Jian \\ School of Economics and Management \\ Leshan Normal University \\ Sichuan Province
}

\author{
Ren Wenju \\ School of Economics and Management \\ Leshan Normal University, \\ Sichuan Province
}

\author{
Ren He \\ Modern Agricultural Investment and Development Corporation \\ Chengdu, Sichuan
}

\begin{abstract}
The Sichuan-Tibetan region has entered into the key period of new-round tourism development. And the enterprise enters, as the principal part of tourism development, should assume the corresponding social responsibilities to promote the stability and Tibetan economic and social development. The related necessity and urgency was clarified in this paper. From the aspect of maintaining the stability of Sichuan-Tibetan region, this paper constructed the hierarchical model of tourism enterprises' social responsibilities for the first time and creatively put forward that the core of social responsibilities is the environmental, ethical and political responsibility. It aimed at promoting tourism enterprises to assume their responsibilities and consciously safeguard the stability of Sichuan-Tibetan region to achieve people's well-being and the prosperity of Tibetan region.
\end{abstract}

Keywords-social responsibility; Sichuan-Tibetan region; tourism corporation

\section{Introduction}

Sichuan-Tibetan region is located in the Northwest Sichuan Plateau, including Ganzi Tibetan Autonomous Prefecture, Aba Tibetan and Qiang Autonomous Prefecture, and Mili Tibetan Autonomous County of Liangshan Yi Autonomous Prefecture. There are 32 counties in total. And the region has a population of 2.18 million, among which 1.3 million are Tibetan, accounting for 60 percent of the total population in SichuanTibetan region. It is the second largest Tibetan region after Tibet in China. It goes that "The border peace is the premise of the country governance, while the stability of Tibetan regions is the guarantee of the border peace”. So the stability of Tibetan regions is significant to the national security. And the security of Sichuan-Tibetan region is a vital part in the whole Tibetan. Per capita regional GDP here is rather low, and tourism plays a significant role in the Tibetan economic and social development. Therefore, it is the fundamental basis for enriching people and Tibetan region and guaranteeing Tibetan stability to develop tourism and promote tourism enterprises better assume their social responsibilities.

\section{CONNOTATION OF TOURISM ENTERPRISES' SOCIAL RESPONSIBILITIES}

Corporate social responsibility (CSR) means that the corporation should assume the responsibility to its staff, consumers, community and environment at the same time of making profits and bear legal responsibilities to its shareholders. CSR requires that a corporation must transcend the traditional concept of regarding the profit as its only target, and it emphasizes the attention to people's value in the production and the contribution to environment, consumers and society.

At first, CSR was raised by Sheldon, an American scholar, who said that CSR should be connected with all people's demands that a corporation is supposed to meet in his works The Philosophy of Management in 1924. Sheldon assumed that corporate responsibility should consist of moral obligations and business operation should be beneficial to the increase of community's interests. The green paper of "Promoting the European Corporate Social Responsibility Framework" issued by EU in 2001 called on corporations should combine the economy, society and environment together in their operation to jointly support the sustainable development of society. In recent 20 years, all the countries and all walks of life have attached great importance to CSR. However, it is a pity that tourism corporation that is greatly dependent on the environment lacks attention to CSR. "There are only 2 percent of the tourism enterprises that participate in the responsible tourism or CSR practice, and tourism corporation lags far behind other industries in CSR practice,” said George in 2010, a British scholar. 


\section{THE NECESSITY AND URGENCY OF FULFILLING SOCIAL RESPONSIBILITY FOR TOURISM ENTERPRISES IN SICHUAN-TIBETAN REGION}

A. The particularity of Sichuan-Tibetan region determined the development of tourism and economy is the foundation to safeguard its social stability.

Sichuan-Tibetan region is one of the poverty-stricken areas with the most severe natural conditions. The 18th National Congress of the CPC clearly put forward the grant goal of building a moderately prosperous society in all aspects by 2020. The Sichuan-Tibetan economic and social development is lagging behind obviously, and from this perspective, the possibility of Tibetan region realizing the goal of comprehensively building a moderately prosperous society on schedule will be directly related to that of the whole nation, the likelihood of radically changing the economic and social development backwardness in ethnic minority areas, and the probability of achieving the common prosperity and progress among all nationalities. Thus, it is urgent to accelerate the economic and social development in Tibetan areas. The promotion of its economic development is of great political, ecological and economic significance, and is the necessary demand of regional sustainable development and building a harmonious society. Tourism industry can enrich the people, and it is helpful to increase the income of the minority and progress of social concepts, as well as promote social stability. Developing tourism is the inevitable choice in Tibetan areas. While the development of tourism economy relies on the participation and development of enterprises. The practice of economic and social development around the world has proved that the corporation is the major force in the economic and social sustainable development, and the principal force to strengthening regional economic vitality. Giving full play to the tourism enterprise and promoting the employment have a strategic influence on the promotion of Sichuan-Tibetan development and stability.

\section{B. The particularity of Sichuan-Tibetan region determined tourism enterprises should prioritize the social responsibility}

Sichuan-Tibetan region, having the most prominent ecological functions, is rich of tourism resources, but most of them are distributed in the plateau or among the high mountains and canyons, where the natural ecology and cultural ecology are rather fragile. If divided by the national theme function, most of the region is restricted development zone due to its rather low carrying capacity of resource and environment. Balanced ecological environment is the bottom line of Sichuan-Tibetan development. The resource structure in this region determined the most appropriate industry is tourism that assumes the major responsibility of improving and protecting Tibetan environment for it is both the consumer of environment resources and participator of environment pollution. However, due to the ignorance of tourism corporation to its social responsibility and excessive pursuit of economic benefits, it in fact caused the damage to tourism resources and environment. Great ethnic complexity also exists in the Sichuan-Tibetan region, so how to protect and inherit Tibetan culture as well as coordinate the enterprise with the minority nationality has been the problem that tourism must solve in its development. So the social responsibility of tourism enterprises must be clarified from the perspective of the maintenance of national stability, the protection of ecological environment and the protection and inheritance of Tibetan culture.

\section{SOCIAL RESPONSIBILITY OF TOURISM ENTERPRISES BASED ON THE STABILITY OF SICHUAN-TiBETAN REGION}

The 5th provision of the new Company Law of China issued in 2005 clearly defined that "The company must abide by laws and administrative regulations, observe social and commercial morality, accept the supervision of government and the public and assume social responsibility.” For the Tibetan tourism enterprises, the core problem of sustainable development is CSR. Shen Pengyi, a doctor in East China Jiaotong University, defined the social responsibility of tourism enterprises as economic responsibility, environmental responsibility, responsibility for tourists and staff, legal responsibility, and philanthropic responsibility. Because tourism enterprises are strongly dependent on natural environment and social environment, and Sichuan-Tibetan region has very fragile ecosystem, complex national conflicts and sensitive politics, these tourism enterprises should confirm the direction, emphasis and range of their social responsibility according to the particularity of Sichuan-Tibetan region. And the environmental, ethical and political responsibility should be their core social responsibility, so the writer designed the hierarchical model of tourism enterprises' social responsibility in Sichuan-Tibetan region as: 


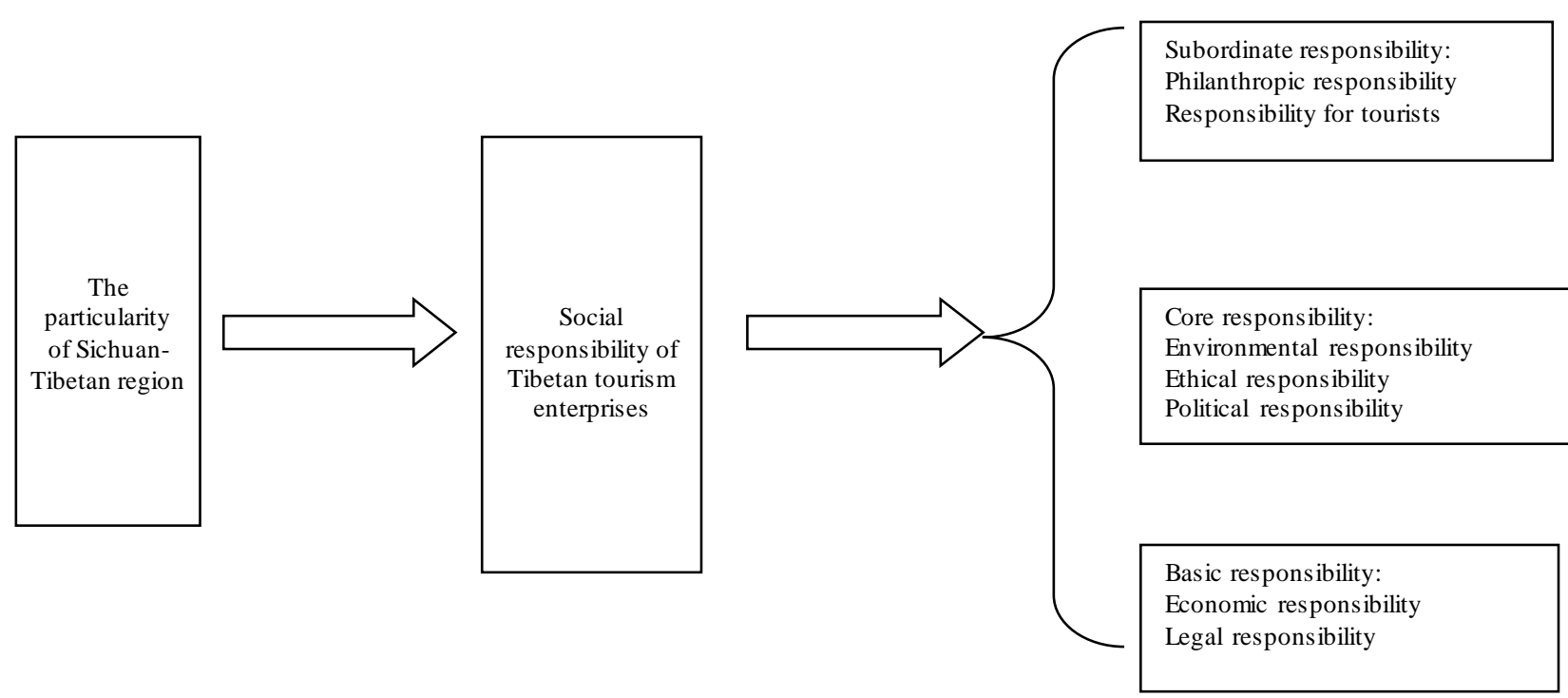

Fig. 1. The hierarchical model of tourism enterprises' social responsibility in Sichuan-Tibetan region

\section{A. Economic responsibility of tourism enterprises in Tibetan areas}

Tourism enterprises should constantly reduce the costs, expand the sales, and provide higher profits and value preservation and appreciation of enterprise capital for investors so as to ensure the legal interests of creditors. This is the foundation of CSR, including sales revenue, net profit and other economic indexes.

\section{B. Legal responsibility of tourism enterprises in Tibetan areas}

Corporate legal responsibility is legalized and it takes the national coercive force as its realistic and potential guarantee, which is a rigid social obligation. For example, pay taxes in accordance with the regulation, assume other responsibilities and obligations prescribed by the government and accept the legal intervention and supervision of the government. Implement the national minimum wage standard, provide legal insurance for enterprise staff and guarantee their health and security. Legal responsibility is the bottom line of performing social responsibility, and the enterprise will get legal sanction if it fails to perform these social responsibilities.

\section{Environmental responsibility of tourism enterprises in Tibetan areas}

The ecology in Sichuan-Tibetan region is very fragile, while tourism is highly dependent on ecology. So environmental responsibility must be the core of Tibetan tourism enterprises' social responsibility, which includes the following three aspects:

1) No harm to the Tibetan environment and meet the legal environmental standards

It has been generally thought that tourism industry, the tertiary industry, belongs to non-smoking industry”, making tourism enterprises ignore the environmental responsibility. However, it is not true. Tourism enterprises use lots of disposal things, emit a lot of washing water and pollutant and always open the air-conditioner, which have polluted the local environment and showed the industry is not environment- friendly. Therefore, Tibetan tourism enterprise should fully realize the harm of its operation behavior on the environment, attach great importance to the environment protection, follow the path of green development and management, launch the ecological tourism, develop low-carbon tourism products, create green restaurants, voluntarily reduce resource and energy consumption to weaken the damage to the environment.

2) Protect and improve the environment of its community

The first one is the tourism development should be oriented with protection and develop within the protection. Due to the fragility of natural environment and value of natural resources, its development must regard the environment protection and efforts to "no artificial tracks" as the concept and endeavor to maintain the biological diversity in Tibetan areas. They cannot develop tourism resources at random because of the sharply increasing of Tibetan tourism enterprises in recent years. Traveling projects should implement the most strict environment evaluation system and scenic sports development should avoid the areas with fragile ecology and protect the core region of natural environment protection. Traveling restaurants are supposed to establish outside.

The second one is green management. Tourist attractions should rationally confirm the travel carrying capacity and tourist scale. The economic benefits should not be the only pursuit at peak season. Organizing and receiving too many visitors should be avoided. Tourism enterprises should protect the tourism resources scientifically and effectively, strengthen the monitoring with environment and actively adopt countermeasures to control the tourist quantity and reduce the environmental loading.

\section{3) Protect and improve the Tibetan environment}

Ecological environment protection in Tibetan areas is a huge process, which needs the large capital investment. Now that tourism enterprises use the high-quality, valuable and fragile tourism resources in Tibetan areas, they should fulfill the obligation of the protection and improvement of the Tibetan environment, perform the philanthropic environment responsibility and protect the environment through donations 
and investment of ecological construction projects to make contributions to the protection of Tibetan environment. This is the embodiment of superior environmental responsibility of tourism enterprises.

\section{Ethical responsibility of tourism enterprises in Tibetan areas}

Ethical responsibility refers to the commitment of tourism enterprises in the social life, requiring that enterprises should do things under the principle of justice and avoid doing things harmful for society.

\section{1) Responsibility for the community}

Firstly, pay attention to the community's interests and promote community development. In the development of Sichuan-Tibetan tourism, the principal part - most of the local Tibetan people fail to have the access to fully participate in the development and obtain the benefits, instead, they have been marginalized gradually. It is the outsides, the organization and group competing for the generated profits with povertystricken areas, that share most of the results of tourism. The community is a key stakeholder in the tourism development. The development strategy of "the whole-area tourism" is implemented in Sichuan-Tibetan region. Natural and cultural resources ethnic minorities live with are regarded as the tourism resource and input in the tourism development. In addition, it directly affords the negative effects of tourism development and operation. Therefore, the community is deserved to get more fair interests sharing. Tourism enterprises should focus on the cooperation and interests sharing with local Tibetan people. Only by fully giving interests to local people and making them get benefits in the related interests chain and become the biggest beneficiaries can they positively support the development of tourism industry and protect rare tourism resources and environment in Tibetan areas.

Secondly, protect and inherit Tibetan culture. Minority culture will be easier to be shocked by the foreign culture in the tourism development due to its fragility and vulnerability compared with the mainstream culture. At present, Tibetan culture have also been badly injured at the same time of bringing benefits for enterprises, so tourism enterprises have the inescapable responsibility for such loss. Tourism operators should follow the principle of seeking truth from facts, and regard preserving the authenticity and integrity of Tibetan culture as the basis and effective protection and inheritance of Tibetan culture as the main objective. Also, they should comprehensively comb the Tibetan cultural resources before the development of ethnical cultural resources, widely consult the opinion of experts on Tibetan, folk customs and tourism, as well as deeply mine and package the Tibetan culture. Local ordinary farmers should be encouraged to fully participate in as the inheritor of Tibetan culture, and become the carrier, launcher and beneficiary of tourism products. And the products should both meet the demand of traveling consumers and authenticity of minority culture to strengthen their identification and a sense of pride with Tibetan culture.

Thirdly, guarantee Tibetan farmer's right to employment. Employment is the foundation of people's livelihood and cornerstone of social stability. Generally speaking, the quality of minority culture is rather low due to the geographical and customs. The sixth census showed that the illiteracy rate in Sichuan-Tibetan region is still over 10 percent, as 14.33 percent. Among them, 12.9 percent is in Aba and 30.17 percent is in Ganzi. From the practice of Tibetan tourism development, low farmers' quality has caused the 'barrier effect of low quality" of inferior competitiveness for tourism job and low adaptability for environment. Objectively, there exists the lack of job equality and the ethnic discrimination of employment in tourism enterprises, which is more likely to breed the dissatisfaction of Tibetan people for a long time. And it will be easier to affect Tibetan stability under the inciting of eternal enemy. Tourism enterprises should fully realize the importance of guaranteeing Tibetan farmers' full employment to ethnic unity and social stability, actively absorb them to be employed and enhance their incomes.

\section{2) Responsibility for its staff}

Staff is the basic and most significant stakeholder of tourism enterprise. Due to the direct feature of tourism consumption, the process is the direct touching between staff and consumers. Staff's service quality is directly related to the consumers' satisfaction degree. Therefore, if there exists no satisfactory staff member, there will be no satisfactory traveling consumers. Tourism enterprises are supposed to bear the corresponding responsibilities and obligations for their staff so as to acquire the sustainable development.

The first one is to create safe and sound working environment and guarantee staff's health and security. Legally purchase the insurance of endowment, medical care and unemployment for staff, respect staff and protect their legal rights and person dignity, guarantee their privacy and equally treat Chinese staff and Tibetan staff.

The second one is to guarantee staff's incomes and welfare. Although the development of tourism has created lots of employment opportunities for Tibetan areas, the peak and off season is very clear due to the geographical environment in the region. Some tourism practitioners' incomes are sharply reduced or even zero in the off season. On the one hand, tourism enterprises should positively adopt series of countermeasures to develop off-season tourism products, create considerable profits and guarantee staff's incomes and welfare; on the other hand, they should establish rational salary system to enhance the tour guide's wage and staff's satisfaction.

The third one is to provide education and training for Tibetan staff. It is obvious that Tibetan farmers' qualities are rather low. In order to ensure their employment and improve the employment quality, tourism enterprises should strengthen Tibetan staff's education and skill training specifically to help them achieve the demand of modern ecological tourism development.

3) Fair competition, voluntarily maintain the order of Tibetan tourism

Tourism competition has been increasingly fierce with the fast development of Tibetan tourism. In order to win the competition advantages and make more profits, there exist lots of unfair competitions among tourism enterprises, affecting the industry style. For instance, some adopt the method of 
reducing price and inferior service quality to make profits, even using violence. Some operators, along the Nine Loop Line, Western Loop LINE and the 318 National Way, lack the integrity and sell fake goods with inferior qualities, having disturbed the order of Tibetan tourism market and brought immense disturbance and loss for tourism corporation. It is necessary for tourism corporation to abide by the acknowledged business ethics, strengthen the industry ethics and launch fair competition under the unified market rules, cracking down on both monopoly pricing and low pricing. Optimize the competition market of tourism market and maintain good market order. Enterprises should have orderly competition and win-win development to jointly make the big cake of tourism market.

\section{E. Political responsibility of tourism enterprises in Tibetan areas}

Complex national conflicts and sensitive politics exist in Sichuan-Tibetan region, which has determined that Tibetan tourism enterprises should also assume one particular social responsibility-political responsibility, meaning the promotion of national unity and maintenance of Tibetan stability.

For a long time, the two main conflicts of insufficient productive force and ethic separatist struggle have been existed in the region. On the one hand, Tibetan areas cannot develop without tourism industry; on the other hand, tourism industry cannot development with our stable social environment. The ethnic conflicts and turbulence in Tibetan areas will directly attack the tourism industry. The government will restrict the entering of tourists around the world, and most tourists will choose to leave here, which will cause great damage to tourism enterprises. The huge effects of the incident on the 14th, March, 2007 on Tibetan tourism are the evidence. Therefore, Tibetan tourism enterprises must obey the overall situation of social stability in Tibetan areas, become the major force for maintaining Tibetan stability, fully support and guarantee Tibetan stability, and create a favorable social environment for the development of tourism enterprises.

The realization of Tibetan stability not only needs the economic development and individual income increases, but also the equality, respect, trust as well as the identification of ideology and culture. Tourism can produce ethnic communication and smooth the communication channel. Besides the development of tourism, these enterprises should spread the advanced ideology and culture and actively promote the unity of the Chinese people and Tibetan people with soft folk methods through tourism practitioners and tourists. Such methods can strengthen the identification of Tibetan people with China and the whole nation with unity, promote the understanding between Sino-Tibetan people and maintain Tibetan harmony and stability.

\section{F. Responsibility for tourists of tourism enterprises in Tibetan areas}

1) To operate with integrity, and provide high-quality tourism goods and service for tourists. There are lots of nonhonest operation behaviors in Tibetan tourism, such as selling fake goods whose costs are lower than the average ones. They obtain the excessive profits though adding optional items in the destination and force tourists to purchase goods as well as take kickbacks from the merchants. Tourism enterprises should build the modern commercial ethics that "modern service industry and the future of tourism industry cannot survive without integrity”. They are supposed to strengthen the discipline and operation standards, and regard the honest operation as the life line of enterprises, customers' satisfaction as the standard to judge the service quality and traveling consumers' demands as the orientation. Different customer groups should be provided tourism products and service with equal quality and price.

2) Respect and safeguard tourists' rights. Tourism enterprises should guarantee traveling consumers' personal and property security, the right to free and fair contract, the right to be respected and the authority to supervise, which can help traveling consumers know the products and service of tourism enterprises as much as possible. Tourists' selection right should be respected, and they can free choose tourism products and service under the premise of fair trading and good tourism consuming environment.

3) Launch the education for traveling consumers and guide visitors to travel in the method of low-carbon. Tourism enterprises should bear the social responsibility and obligations to educate and guide visitors to restrain their own behaviors. Visitors' qualities can be trained and enhanced through launching the consumer education so that their civilized traveling can reduce the bad effects on environment. The related education content includes: communication ethics education with the attention to respecting Tibetan culture, habit and belief; ecological ethics education with the emphasis of voluntarily promoting environment protection for tourisms, launching low-carbon tourism, protecting Tibetan ecological environment and timely stopping the behavior of destroying environment; consumption ethics education with the orientation of guiding tourists to have green consumption, avoid luxury consumption and reduce waste emission.

\section{G. Philanthropic responsibility of tourism enterprises in Tibetan areas}

Philanthropic responsibility means that the enterprise, as a good enterprise citizen, is willing to input resource, provide social service and enhance the life quality according to the social expectation. Its philanthropic responsibility is volunteering, which is the embodiment of superior CSR. Such responsibility is helpful to enhance enterprises' image and strengthen consumers' identification and enterprise cohesion to bring enterprise obtain more social resources and long benefit for its own development. Meanwhile, it can promote social justice as well as maintain national unity and social peace.

\section{1) Pay attention to disadvantaged groups}

Sichuan-Tibetan region is one of the most poorest areas in Sichuan Province. Some people there have constituted "disadvantaged groups". Tourism enterprises can adopt various methods to aid these people, such as fund the patients with local disease, left-behind children and the disabled through the foundation. Enterprises can help them making life and production skill training and strengthen the survivability. They can also launch mental counseling, instruct them to participate in public activities, pass the positive energy and give them mental support to ignite their life hope. 


\section{2) Charitable donations}

Natural disasters often occur in the Sichuan-Tibetan region, such as the earthquake, debris flow and hail. When such major disaster happens, tourism enterprises should actively donate funds and goods and offer the human resource, facility and technology within their abilities, to assume their own philanthropic responsibility.

3) Participate in the public welfare activities

Tourism enterprises cannot develop without the support of social environment. From the perspective of justice, since enterprises consume social resources, they should return to society. The participation of tourism enterprises in charitable activities is beneficial to the promotion of social justice and Tibetan stability as well as the establishment of harmonious external environment. Tourism enterprise operators should build correct concept of public welfare and warmly participated in social charitable activities to serve society. They can set up "the prize of environment protection" combining their own specialties and social hot topics, organize disadvantaged groups to have a free trip and staff to promote the environment protection, provide voluntary service for visitors, and perform colorful cultural activities for the community.

\section{CONCLUSION}

The stability of Sichuan-Tibetan region is of great significance to the stability of the whole Sichuan Province, and its stability is the premise of tourism' long development. The particularity of this region has determined the core of tourism enterprises' social responsibility should be the environmental, ethical and political responsibility. At the same time of focusing on the role of tourism enterprise development in the promotion of Tibetan economic and social development and people's livelihood, driving tourism enterprises to truly fulfill social responsibility and enhancing the long peace of SichuanTibetan region should become the common target of the tourism enterprise, the Tibetan government, the province and the whole nation.

\section{REFERENCES}

[1] Sichuan University. Report on the Tourism Development of the Whole Sichuan-Tibetan Region in 2014[R]. 2015

[2] Yang Jiancui. Research on the Promotion Tourism on the Urbanization in the Ethnic Regions of Western Sichuan Province[D]. Doctoral Dissertation of Southwest University for Nationalities 2012

[3] Wijk J, Persoon W. A long- haul destination: Sustainability reporting among tour operators [J]. European Management Journal, 2006, 24(6): 381-395.

[4] Tang Hui. Empirical Research on the Restaurants' social responsibility and Consumers' Purchase Intention[D]. Doctoral Dissertation of Jinan University 2011 